\title{
Electrochemical Determination of Diethylstilbestrol in Animal Food Using a Poly Polylysine/Graphene Modified Electrode
}

\author{
Yilei Wang ${ }^{1}$, Meifeng Chen ${ }^{2, *}$, Huiping $\mathrm{Lv}^{2}$, Xinying Ma ${ }^{2, *}$ \\ ${ }^{1}$ College of agriculture and engineering of Heze University, 2269 N.Daxue Rd. Heze 274015, China. \\ ${ }^{2}$ Department of Chemistry and Chemical Engineering of Heze University, 2269 N. Daxue Rd. Heze \\ 274015, China. \\ *E-mail: hezexueyuanhx@163.com,cmf3699@163.com
}

doi: $10.20964 / 2019.06 .35$

Received: 13 January 2019 / Accepted: 5 April 2019 / Published: 10 May 2019

\begin{abstract}
A polylysine/graphene modified electrode was prepared. The electrochemical behaviour of diethylstilbestrol on the surface of this electrode was studied. A new method for the direct determination of diethylstilbestrol in food was developed. The experimental results showed that there was a pair of reversible redox peaks for diethylstilbestrol on this modified electrodes in $0.5 \sim 1.0 \mathrm{~V}$ range in a phosphate buffer solution ( $\mathrm{pH}$ 3.0). Compared with the effects of a glassy carbon electrode and a polylysine modified electrode, it was concluded that the polylysine/graphene modified electrode has a higher electrocatalytic effect on the oxidation of diethylstilbestrol. In the range of $8.00 \times 10^{-8} \sim 1.00 \times 10^{-5} \mathrm{~mol} / \mathrm{L}$, the concentration of diethylstilbestrol was directly proportional to its oxidation peak current, and the detection limit is $1.20 \times 10^{-9} \mathrm{~mol} / \mathrm{L}$. The relative standard deviation ( RSD ) was $1.7 \%$ over six parallel tests. The modified electrode had a high sensitivity and good selectivity and better stability than the control electrode and could be used to determine the concentration of diethylstilbestrol in beef, mutton and milk with recovery rates of $97.0 \% \sim 103.0 \%$.
\end{abstract}

Keywords: polylysine; graphene; modified electrode;cyclic voltammetry;diethylstilbestrol

\section{$\underline{\text { FULL TEXT }}$}

(C) 2019 The Authors. Published by ESG (www.electrochemsci.org). This article is an open access article distributed under the terms and conditions of the Creative Commons Attribution license (http://creativecommons.org/licenses/by/4.0/). 